\title{
Editorial
}

\section{Digital Cultural Heritage}

\author{
Cristina Portalés ${ }^{1, *}{ }^{\mathbb{C}}$, João M. F. Rodrigues ${ }^{2}$, Alexandra Rodrigues Gonçalves ${ }^{3}$, Ester Alba ${ }^{4}$ and \\ Jorge Sebastián ${ }^{4}$
}

1 Institute of Robotics and Information and Communication Technologies (IRTIC), Universitat de València, 46980 València, Spain

2 LARSyS \& Instituto Superior de Engenharia, University of the Algarve, 8005-139 Faro, Portugal; jrodrig@ualg.pt

3 Escola Superior de Gestão, Hotelaria e Turismo, University of the Algarve, 8005-139 Faro, Portugal; alexandra.goncalves@cultalg.gov.pt

4 Department of Art History, Universitat de València, 46010 València, Spain; esther.alba@uv.es (E.A.); jorge.sebastian@uv.es (J.S.)

* Correspondence: cristina.portales@uv.es; Tel.: +34-963-543-557

Received: 7 September 2018; Accepted: 10 September 2018; Published: 11 September 2018

\section{Introduction}

Most contemporary thinkers agree that we are going through a time of historical change, building a different concept and model of social interrelation. Our ways of life and work have changed, as have the ways in which we communicate and relate to each other.

Likewise, an increasing consensus indicates the need to reconfigure traditional social and cultural structures. The Internet, the virtual social networks, and the Information and Communication Technologies (ICTs) have coalesced into a new collective consciousness-a world intercommunicated from the local to the global [1]. The fusion of tradition, culture, history, and legacy with technology, innovation, and interaction provides an attractive system that serves both as an artistic expression and as a fundamental tool for diffusion in cultural institutions [2]. For instance, the usage of interactive technologies such as virtual reality (VR) or augmented reality (AR), combined with multidimensional or multimodal representations [3], provides a significant novelty. User interaction offers a broader perspective, making people more aware of their actions, helping them become the true center of the application. It also enables interactive artistic expression through alternative realities, as well as narration supported by the use of virtual avatars [4].

In a certain way, this new trend involves a break with former negative developments within cultural policies of exhibition and museum spaces. The 1980s saw the rise of emblematic museums, considered more as a spectacle than as a space for the protection of heritage assets. In them, the architectural object mattered more than the ability to reach the public. The rise of contemporary art museums in the 1990s led to a disdainful look at the museum as a conservative art institution, and favored their understanding as mere cultural centers with multi-purpose rooms. Fortunately, this discourse has been superseded; there is now a greater concern to work with collections in order to build new resources and new museum narratives. ICTs are an effective and necessary ally in these tasks [5].

Currently, museums are considered as institutions based on the transmission of knowledge, whose priority is to set culture within the reach of every society, as centers of digital exchange, and as open spaces of intergenerational dialogue [6-9]. In this paradigm shift, the evaluation of the user experience is increasingly important. Improving the understanding of cultural sites or museums through mobile applications requires a complex but necessary task: the assessment of digital applications and their reception by users. Monitoring the acquisition of knowledge is a crucial 
tool in order to propose relevant recommendations for the design of digital experiences for cultural, educational, and recreational purposes [10].

In the heritage field, one can speak of art labs or history labs, but more specifically of heritage labs as a process of innovation in society/heritage relations, in a constant search for strong social involvement [11]. This search for the creation of cultural, social, and political systems is based on favoring fair and sustainable practices through experiential and participatory approaches. Awareness-raising processes are becoming commonly generated through innovative access to information systems or in the creation of new cultural containers. A clear example is the creation of cultural routes that are developed on the territory, while also offering rich spatio-temporal information, visualizing and helping to understand the historical processes, the changes, and evolution of heritage sites.

In recent years, UNESCO [12] has privileged the concept of "integral heritage", which exceeds the isolated building or monument [13]. This understanding of heritage as an integral reality requires a collective perception and the establishment of cultural networks that expand the range of perception, combining monuments, heritage sites, museums, natural landscapes, cultural landscapes, ethnographic realities, historical sites, collective memory, and cultural routes [14]. The goal is the public appreciation of the heritage, the understanding of the cultural and educational dimension in a single universe, interconnected in a set of multinodular networks. In this objective, new technologies can become an important and effective ally.

Within this context, this Special Issue was devised on a set a shared assumptions. Cultural Heritage $(\mathrm{CH})$ is an essential expression of the wealth and diversity of human cultures, and therefore its documentation, interpretation, restoration, and dissemination are considered to be crucial tasks. Information and Communication Technologies (ICTs) provide researchers with powerful tools to deal with the digital acquisition, storage, conservation, recreation, reconstruction, and representation of $\mathrm{CH}$ assets, both tangible and intangible. Every day, new initiatives are materializing this symbiosis between ICT and Social Sciences and Humanities (SSH) - for example, for the accurate multi-dimensional documentation of our cultural legacy, the processing of large amounts of data to identify new correlations among digital heterogeneous collections, or the increase of $\mathrm{CH}$ awareness by means of advanced representation and interaction (e.g., visual, tangible, etc.) approaches. Due to the increasing capabilities of new technologies that triggers the growing complexity in the digital documentation and representation of $\mathrm{CH}$, new challenges arise regarding its preservation over time, re-use, and study.

\section{Papers Published in This Special Issue}

The essays received, reviewed, and accepted here study these topics from different perspectives, some of them technological in nature (e.g., ICT, architecture, etc.), while others approach issues from the Humanities and the Social Sciences (e.g., art history, conservation, etc.). Six are original papers, one is a communication, and one a review. They all unpack the relevance of digital $\mathrm{CH}$ in the current research panorama. In the following paragraphs, an outline and short discussion on these papers is provided, highlighting their main findings.

Multimodal and Interactive technologies play an important role in the documentation, preservation, and dissemination of cultural assets. For instance, by means of AR and VR technologies, cultural assets can be relocated and recontextualized. This can help users to understand their original location, scale, and function, thus better relating them to the cultural identities that originated them, as shown by some papers in this issue. "TinajAR: An Edutainment Augmented Reality Mirror for the Dissemination and Reinterpretation of Cultural Heritage" [15] describes a system dealing with ceramic heritage, designed to be both an edutainment application and an artistic piece. TinajAR features an AR mirror metaphor [16,17] (i.e., users see themselves immersed in an augmented environment). As an artistic expression, TinajAR seeks to reinterpret an ancient type of cellar called a calado, which was used to store wine in northern Spain. It is an example of AR opening up a complete set of new 
possibilities for $\mathrm{CH}$, including the virtual transformation of physical elements. "A Novel Immersive VR Game Model for Recontextualization in Virtual Environments: The $\mu$ VRModel" [18] puts forward a new model for VR games, named $\mu \mathrm{VR}$. By combining real-walking techniques and an adaptive, game-driven, multi-scale progression, it allows the creation of immersive VR applications targeting re-contextualization activities that require users to relocate virtual cultural objects in their former locations. The $\mu$ operator performs a liquid and adaptive miniaturization of the user each time they correctly place a given item onto its target location. Furthermore, the model aims to minimize motion sickness while fully exploiting the physical tracked area and augmenting the understanding of user experiences within the virtual world.

In a different way, another paper involving relocation and recontextualization is "Behind the 3D Scene: A GIS Approach for Managing the Chronological Information of Historic Buildings" [19]. In this case, chronological recontextualization plays an important role. Historic buildings are representations of cultural systems over time. Therefore, it is important to shed light on the chronological information about any given historical building, and thus show the descriptions of its different (re)compositions for different moments. The authors argue that this allows a holistic understanding of historical changes and, in turn, supports the planning of restoration projects, providing a complete documentary archive. They also propose a methodology that makes use of Geographic Information Systems (GIS) and develops a digital "container" as a 3D digital model for the archiving of a building's chronological information. It covers both the geometric and spatial aspects, as well as the historical sources and their reliability. The core technology for this study is architectural 3D modeling, so relevant in the $\mathrm{CH}$ sector. This is also highlighted in the paper entitled "A Review of Heritage Building Information Modeling (H-BIM)" [20], which offers an extensive review focused on Heritage BIM (H-BIM) - a kind of 3D model that follows the BIM standard, contextualized for the heritage sector. The authors show that the complex modeling of cultural heritage through commercial BIM software leads to the consideration of the H-BIM concept, which pursues the modeling of architectural elements according to artistic, historical, and constructive typologies. The paper reviews the literature on H-BIM and its effective implementation in the cultural heritage sector, also exploring the effectiveness and usefulness of the existing methodologies.

Mobile phones are being increasingly used in the context of museums and exhibition spaces, maybe because of their light weight, their increased computational capabilities (which allow embedding interactive applications with rich graphics), or the fact that most people have their own device. Among other reasons, they are highly useful in generating new museum narratives, as highlighted by the paper "Flow, Staging, Wayfinding, Personalization: Evaluating User Experience with Mobile Museum Narratives" [21]. Its main challenge is to report on the evaluation of prototype narrative "guides" based on mobile devices, designed, developed, and implemented as part of a research project at the Acropolis Museum in Athens, Greece. It aimed to make museums more attractive and relevant to a wider range of visitors by creating personalized interactive storytelling experiences. The authors highlight the complexity of understanding users' experience, and what makes it effective in the rich context of a cultural setting. They underscore the relevance of proper design, monitoring, and evaluation, where different profiles of visitors and users need to be considered. Their conclusions are in some ways aligned with the paper "Enhancing the Appreciation of Traditional Chinese Painting Using Interactive Technology" [22], which reports on field studies of a prototype tablet application about Chinese painting. First, authors present a cultural appreciation study where they explore the specific approach of cross-cultural aesthetics, mapping potential insights for a prototype design. Secondly, they show the design of a tablet application and the results of focus group studies to explore the technology that supports cross-cultural audiences' aesthetic appreciation and engagement with traditional Chinese painting. Their aim is to offer valuable transferrable insights about the design of interactive technology that enables the appreciation of traditional art.

This framework raises new challenges as well as the establishment of new canons. Such a debate is introduced in the paper "Canon, Value, and Cultural Heritage: New Processes of Assigning Value in 
the Postdigital Realm" [23]. It aims to provide some reflections on the mechanisms of canon formation in the context of the web as a new laboratory of cultural production. It also intends to feed the critical discussion about how the so-called postcanonical age unfolds, under various forms: hypercanonization, socialdecanonization, and transcanonization. The author opens interesting questions for this debate, such as "who owns the cultural values in the postdigital society?" or "who holds now the authority and power to establish the new canons and legitimizing discourses?"

Finally, "Interactive Tools for the Preservation, Dissemination and Study of Silk Heritage-An Introduction to the SILKNOW Project" [24] provides an introduction to a project that will produce an intelligent computational system in order to improve the understanding of European silk heritage. To that end, it will make use of different interactive technologies, such as a web portal with a multilingual thesaurus, spatio-temporal visualizations of objects related to silk heritage, or a virtual loom that is able to digitally weave ancient silk textiles.

In summary, this Special Issue explores the role of new and interactive technologies in digital cultural heritage, including virtual reality, augmented reality, mobile technologies, web-based networks, GIS, or 3D assets representation, among others. It addresses the promise of these technologies for museums, helping to bring $\mathrm{CH}$ content closer to the public while enhancing their experiences thereof. As editors of this Special Issue, we feel that our goals have been successfully met, as the papers provide very diverse reflections of the current research trends in this area.

Author Contributions: Writing—Original Draft Preparation, C.P., E.A., J.S.; Writing—Review \& Editing, C.P., J.M.F.R., A.R.G., E.A., J.S.

Funding: This research received no external funding.

Acknowledgments: The editors thank the various contributors, reviewers and journal staff at Multimodal Technologies and Interaction for making this Special Issue a success.

Conflicts of Interest: The authors declare no conflict of interest.

\section{References}

1. Alba Pagán, E. Fundamentos para la gestión del patrimonio cultural. In El Desarrollo Territorial Valenciano: Reflexiones en Torno a Sus Claves; Universitat de València: València, Spain, 2014.

2. De Tapol, B. La necesaria adaptación de la conservación preventiva al concepto de sostenibilidad con especial atención a las herramientas de gestión. Patrim. Cult. Esp. 2013, 7, 81-90.

3. Portalés, C.; Casas, S.; Alonso-Monasterio, P.; Viñals, M.J. Multi-dimensional acquisition, representation, and interaction of cultural heritage tangible assets: An insight on tourism applications. In Handbook of Research on Technological Developments for Cultural Heritage and Etourism Applications; IGI Global: Hershey, PA, USA, 2018; pp. 72-95.

4. Stovel, H. Monitoring world heritage. In World Heritage Centre and ICCROM, Rome (World Heritage Paper No. 10); UNESCO World Heritage Centre and ICCROM: Paris, France, 2004.

5. Desvallées, A.; Mairesse, F. Key Concepts of Museology; Armand Colin: Paris, France, 2010.

6. Adie, B.A.; Hall, C.M. Who visits world heritage? A comparative analysis of three cultural sites. J. Heritage Tour. 2017, 12, 67-80. [CrossRef]

7. Ashworth, G.J.; van der Aa, B.J. Strategy and Policy for the World Heritage Convention: Goals, Practices and Future Solutions. Available online: http://www.mu.edu.et/iphc/images/liblary/Heritage/Heritage_ Culture_and_Tourism/Managing_World_Heritage_Sites.pdf\#page=174 (accessed on 7 September 2018).

8. Boyd, S. Cultural and heritage tourism in canada: Opportunities, principles and challenges. Tour. Hosp. Res. 2002, 3, 211-233. [CrossRef]

9. Timothy, D.J.; Boyd, S.W. Heritage tourism in the 21st century: Valued traditions and new perspectives. J. Heritage Tour. 2006, 1, 1-16. [CrossRef]

10. Shipley, R.; Kovacs, J.F. Good governance principles for the cultural heritage sector: Lessons from international experience. Corp. Gov. Int. J. Bus. Soc. 2008, 8, 214-228. [CrossRef]

11. Sebastián Lozano, J. Digital Art History at the Crossroads. Available online: https://edoc.hu-berlin.de/ bitstream/handle/18452/19405/Lozano\%20final.pdf (accessed on 7 September 2018). 
12. Managing Cultural World Heritage. Available online: https://whc.unesco.org/en/managing-culturalworld-heritage/ (accessed on 7 September 2018).

13. Ryan, J.; Silvanto, S. A brand for all the nations: The development of the world heritage brand in emerging markets. Mark. Intell. Plan. 2011, 29, 305-318. [CrossRef]

14. Arpin, R. Notre Patrimoine, un Présent Du Passé. Available online: http:/ /bel.uqtr.ca/1239/1/6-19-68120060117-1.pdf (accessed on 7 September 2018).

15. Martínez, B.; Casas, S.; Vidal-González, M.; Vera, L.; García-Pereira, I. Tinajar: An edutainment augmented reality mirror for the dissemination and reinterpretation of cultural heritage. Multimodal Technol. Interact. 2018, 2, 33. [CrossRef]

16. Giner Martínez, F.; Portalés Ricart, C. The augmented user: A wearable augmented reality interface. In Proceedings of the International Conference on Virtual Systems and Multimedia (VSMM'05), Ghent, Belgium, 3-7 October 2005.

17. Portalés, C.; Gimeno, J.; Casas, S.; Olanda, R.; Martínez, F.G. Interacting with augmented reality mirrors. In Handbook of Research on Human-Computer Interfaces, Developments, and Applications; IGI Global: Hershey, PA, USA, 2016.

18. Fanini, B.; Pagano, A.; Ferdani, D. A novel immersive vr game model for recontextualization in virtual environments: The $\mu$ vrmodel. Multimodal Technol. Interact. 2018, 2, 20. [CrossRef]

19. Saygi, G.; Agugiaro, G.; Hamamcioglu-Turan, M. Behind the 3D scene: A gis approach for managing the chronological information of historic buildings. Multimodal Technol. Interact. 2018, 2, 26. [CrossRef]

20. López, F.; Lerones, P.; Llamas, J.; Gómez-García-Bermejo, J.; Zalama, E. A review of heritage building information modeling (h-bim). Multimodal Technol. Interact. 2018, 2, 21. [CrossRef]

21. Roussou, M.; Katifori, A. Flow, staging, wayfinding, personalization: Evaluating user experience with mobile museum narratives. Multimodal Technol. Interact. 2018, 2, 32. [CrossRef]

22. Zhao, S.; Kirk, D.; Bowen, S.; Wright, P. Enhancing the appreciation of traditional Chinese painting using interactive technology. Multimodal Technol. Interact. 2018, 2, 16. [CrossRef]

23. Rodríguez-Ortega, N. Canon, value, and cultural heritage: New processes of assigning value in the postdigital realm. Multimodal Technol. Interact. 2018, 2, 25. [CrossRef]

24. Portalés, C.; Sebastián, J.; Alba, E.; Sevilla, J.; Gaitán, M.; Ruiz, P.; Fernández, M. Interactive tools for the preservation, dissemination and study of silk heritage-An introduction to the silknow project. Multimodal Technol. Interact. 2018, 2, 28. [CrossRef] 